\title{
Risk Spillovers in Oil-Related CDS, Stock and Credit Markets
}

\author{
Shawkat Hammoudeh \\ Lebow College of Business \\ Drexel University \\ USA \\ Tengdong Liu \\ Lebow College of Business \\ Drexel University \\ USA \\ Chia-Lin Chang \\ Department of Applied Economics \\ Department of Finance \\ National Chung Hsing University \\ Taichung, Taiwan \\ Michael McAleer \\ Econometric Institute \\ Erasmus School of Economics \\ Erasmus University Rotterdam \\ and \\ Tinbergen Institute \\ The Netherlands \\ and \\ Department of Quantitative Economics \\ Complutense University of Madrid
}

April 2011

*For financial support, the third author wishes to thank the National Science Council, Taiwan, and the fourth author wishes to thank the Australian Research Council, National Science Council, Taiwan, and the Japan Society for the Promotion of Science. 


\begin{abstract}
This paper examines risk transmission and migration among six US measures of credit and market risk during the full period 2004-2011 period and the 2009-2011 recovery subperiod, with a focus on four sectors related to the highly volatile oil price. There are more long-run equilibrium risk relationships and short-run causal relationships among the four oil-related Credit Default Swaps (CDS) indexes, the (expected equity volatility) VIX index and the (swaption expected volatility) SMOVE index for the full period than for the recovery subperiod. The auto sector CDS spread is the most error-correcting in the long run and also leads in the risk discovery process in the short run. On the other hand, the CDS spread of the highly regulated, natural monopoly utility sector does not error correct. The four oil-related CDS spread indexes are responsive to VIX in the short- and long-run, while no index is sensitive to SMOVE which, in turn, unilaterally assembles risk migration from VIX. The 2007-2008 Great Recession seems to have led to "localization" and less migration of credit and market risk in the oil-related sectors.
\end{abstract}

JEL: C13, C22, G1, G12, Q40.

Keywords: Risk, Sectoral CDS, VIX, SMOVE, MOVE, Adjustments. 


\section{Introduction}

Oil ranks among the most volatile non-agricultural commodities, particularly in recent years. Its price dropped from \$147/barrel in July 2008 to \$32/barrel in March 2009, and then climbed to more than $\$ 100 /$ barrel in the first quarter of 2011 . Although the oil price is a major source of instability in the world economy, it is not a measure of credit risk, fear or a gauge of future economic health in the oil exploration and production sectors, related sectors such as the natural gas, utility, chemicals and auto sectors, or the stock and bond markets. Credit Default Swaps (CDS) for these oil and oil-related sectors measure expected credit risk, fear, greed and the future economic health of these sectors, which is relevant information that the oil price may measure. ${ }^{1}$ On the other hand, indexes such as VIX and SMOVE measure of market risk in the form of expected volatility in the equity, bond and swap options markets. These market risks carry systematic risk that can affect sector CDS risks, among others. It assembles risk information on events related to more than the stock market. In fact, VIX increased by more than $30 \%$ in the week that followed the magnitude 9.0 Great Eastern Japan Earthquake on March 11, 2011

A CDS index is a highly liquid, standardized credit security that trades at a very small bid-ask spread. Oil-related CDSs can be efficient in processing information on evolving risks in the oil and oil-related sectors, and probably the rest of the economy (see Norden and Weber, 2004; Greatrex, 2008, among others). The magnitude of the oil and oil-related sector credit spreads gauges the default risk exposure of the firms that comprise these sectors. A widening of a CDS spread in response to certain oil or credit events indicates an increase in

\footnotetext{
${ }^{1}$ Oil VIX, which measures risk and fear in the oil sector, is still in its infancy and its data series are presently inadequate for quantitative analysis like ours. Still, equity and bond VIXs should have some bearing on the oil VIX.
} 
the level of credit risk in the pertinent sectors, while a narrowing in the spread reveals a decrease in the credit risk.

The market for CDSs is enormous. The notional values outstanding surveyed by ISDA ballooned from $\$ 918.81$ billion at the end of 2001 to $\$ 62.173$ trillion by the end of 2007 , before falling to $\$ 30.428$ trillion by the end of 2008 . $^{2}$ The market value is more than two trillion. The composition in the USA of the notional value outstanding in 2008 is $\$ 15.5$ trillion, which is equal to the size of US GDP, but is greater than the national debt and the $\$ 11$ trillion home mortgage market, of which only $\$ 1$ trillion is the subprime part. As swaps have proliferated so rapidly, experts argue that a hiccup in this market could set off a chain reaction of losses in financial institutions, making it even more difficult for borrowers to obtain loans that facilitate economic activity. ${ }^{3}$

Other measures of risk are VIX and MOVE/SMOVE, which have inverse relationships with the stock, bond and mortgage markets. These measures may relate to credit risk gauged by CDS indexes, which include liquidity and default components of the real sectors. The volatility index (VIX) is an index which measures expectations of volatility of the S\&P 500 index over one month. Higher values of this volatility index suggest that investors expect the value of the S\&P 500 index to fluctuate wildly - up, down, or both - in the next thirty days. The VIX index is also known as the "fear" index in the stock market as a high value reflects uncertainty about future stock prices. Interestingly, VIX hit its historic high of 89.53 on October 24, 2008, immediately after the oil price reached its historic peak in July of the same

\footnotetext{
${ }^{2}$ http://www.isda.org/statistics/pdf/ISDA-Market-Survey-annual-data.pdf.

${ }^{3}$ http://www.nytimes.com/2008/02/17/business/worldbusiness/17iht-17swap.10104972.html
} 
year, three months after the oil price reached all time high. It will be useful to determine the dynamic relationships between market and credit risks generated by changes in the oil price, oil-related CDS sector indexes and VIX. The information should be valuable to investors in these sectors and to the energy regulators that regulate this sector.

As the CDS contracts are protection insurance against adverse credit events in the credit markets, it will also be interesting to examine how oil-pertinent CDS indexes are related to expected risk in the bond market, as measured by the Merrill Lynch Option Volatility Estimate (MOVE) Index and the swap market, as represented by the swaption MOVE (SMOVE) index. MOVE is a yield curve weighted index of the normalized implied volatility on one-month Treasury options with $40 \%$ on the 10 -year Treasury and $20 \%$ on the other Treasury maturities. SMOVE measures volatility on options for US non-Treasury interest-rate swaps with maturities of one to ten years, and are used to speculate on and hedge interest rate risk. MOVE/SMOVE signals interest rate movements as uncertainty change in the bond markets, and also assembles information regarding concerns over inflation, deflation, and a massive rolling of the Government debt.

There has been a discrepancy between MOVE and VIX since the collapse of Lehman Brothers, where VIX slowly falls methodically to pre-bankruptcy levels, while MOVE volatility has remained elevated, perhaps due to quantitative easing. As indicated above, it will be valuable to discern the impact of oil, credit and equity events on the oil-related CDS, stock, and bond/mortgage markets. The information derived from examining a complex of multiple measures of risk, where risk arises from different sources, should be useful for oil companies, investors, creditors and energy regulators, particularly at times of risky events, such as the BP spill in the Gulf of Mexico in 2010, the GM bankruptcy, geopolitics in the 
Middle East and the radiation leak in the Japanese nuclear reactors arising from the tsunami in March 2011.

The objectives of this paper are to: (1) determine how the four oil and oil-related sector CDS spreads interrelate with each other and to events in the oil market, as represented by futures oil price movements; and (2) explore the risk feedbacks in the multiple-risk complex between the oil-related CDS spreads, VIX and the bond/mortgage market MOVE/SMOVE.

The paper is organized as follows. Section 2 discusses the data and descriptive statistics. Section 3 presents a review of the literature. Section 3 presents the empirical model and analyzes the empirical results. Section 5 gives some concluding comments.

\section{Data and Descriptive Statistics.}

The data set includes the closings for the West Texas Intermediate (WTI) futures price and the seven different measures of risk in the vast risk complex examined in this paper. The risk measures are four for the oil and oil-related CDS sectors (namely auto, chemicals, oil and gas, and utility), and for the one-month equity VIX index and the one month MOVE/SMOVE index. ${ }^{4}$ We could not include the oil VIX as a measure of risk and fear in the oil market because of its excessively short time period compared with the other variables, which is from January 1, 2004 to January 21, 2011.

\footnotetext{
${ }^{4}$ Each index series has a given number of reference entities at a fixed coupon. The coupon is determined prior to the onset of each index series, and is the current spread of the underlying reference entities that equate the value of the index to par value $(100 \%)$ at the time of calculation. The levels of the indices are calculated at the end of each business day at around $5: 15 \mathrm{pm}$.
} 
The CDS sector indices, which are based on the most liquid 5-year term, are equally weighted and reflect an average mid-spread calculation of the given index's constituents. The proprietary indices are rebalanced every six months to better reflect liquidity in the CDS market. The identification of the CDS sector indices follows the DJ/FTSE Industry Classification Benchmark (ICB) supersectors as their basis, and reflects the price performance of a basket of corporate 5-year CDSs within a given sector. As stated, the data for the CDS sector indices are available from 2004 only. The years 2004-2007 of the full sample for the CDS market were rapid growth years. However, the years 2008-2009 were troubling years for this market, which experienced simulative packages and QE1 and QE2.

As indicated above, the equity VIX is an index which measures expectations of volatility of the S\&P 500 index, and typically moves in an adverse direction to the latter. It assembles risk information on events related to more than the stock market. In fact, VIX increased by more than $30 \%$ in the week that followed the magnitude 9.0 Great Eastern Japan Earthquake on March 11, 2011. This index has sentiment extremes: (30-32) signals excessive bearishness that foreshadows bullish reversals, while (16-18) signals excessive bullishness that foreshadows bearish reversals. On the other hand, the one-month MOVE index is a yield curve weighted index of the normalized implied volatility on one-month Treasury options, with a $40 \%$ on the 10-year Treasury and $20 \%$ on each of the other 2-30 year Treasury maturities. It trades between two extremes: 80, indicating extreme complacency which presages a market problem, and 120, which signals extreme fear. Moves to the extremes are quite rare for this credit index.

The descriptive statistics for both the (log of) levels and first logarithmic differences are presented in Table 1 (Panels A and B, respectively). The average percentage change over the 
sample period is the highest for the utility CDS index, followed by the oil/gas sector, while it is the lowest for the auto and chemicals sectors. The average return for the futures oil prices is much higher than for any of the CDS sector indexes. It is interesting to note that the average percentage change for VIX is lower than for MOVE/SMOVE, and both are much lower than for the oil-related CDS indexes.

\section{[Table 1 goes here]}

In terms of historical volatility, as measured by standard deviation, the highest percentage change volatility is for the auto CDS index, followed by oil/gas CD index, while the lowest is for the CDS index for utility, followed by chemicals. It is interesting to note the volatilities for the CDS indexes of utility, chemicals and oil/gas, and the oil price are very similar. Unexpectedly, the historical volatility of VIX is the highest among the seven variables. The auto and chemicals CDS indexes and the oil price are skewed to the left, suggesting that the mass of the distribution is concentrated on the right of the figure, and they have a few extremely low values. This means the spreads are bunched up on the high end of the spread scale. In comparison, the utility, oil and gas CDS indexes, VIX and MOVE/SMOVE are skewed to the right.

The correlation coefficients in Table 1 are provided for the log values and for returns. The correlations are very high for the levels. In fact, it is almost $99 \%$ between the levels of MOVE and SMOVE over the historical period (Table 2 - Panel A). However, the correlations between the first log differences (returns) of the other risk measures and with the oil price are low, with the exception of the correlation between MOVE and SMOVE, which 
exceeds $81 \%$ (panel B). This suggests that these risk measures have different risk components and measure different types of risk.

\section{[Table 2 goes here]}

The kurtosis results indicate that the distributions of the spreads are more platykurtic (flat) for the levels, while more leptokurtic (peaked with fat tails) for the returns or first log differences. The Jarque-Bera Lagrange multiplier statistics reject the null hypothesis of a normal distribution, which is consistent with the statistics for skewness and kurtosis for most speculative assets.

The ADF and Phillips-Perron (PP) unit root tests for the intercept and intercept plus trend were calculated for all eight variables. The results indicate that all variables have unit roots or are I(1). One may contend that VIX is an implied option volatility index, and thus is a proxy for option prices. This explains why VIX has unit root behavior. Based on those findings, we model all measures of risk and the oil prices in logarithmic differences. This paves the way for conducting cointegration tests.

\section{Review of the Literature}

Given the short history of CDS index spreads, the limited availability of data and the raging debate over the social benefits and costs of CDSs, the literature on these credit derivatives is still quite sparse, particularly after the 2008 financial and 2010 sovereign debt crises. Clearly, there is substantial scope for contribution to this area. The recent literature examines the difference between spreads in the cash/asset market and the CDS credit market, known as the "basis" (Das and Hanouna, 2006). Longstaff et al. (2005) examined the basis 
using an approach that extracted the corporate bond-implied CDS spreads, compared it with the actual market CDS spreads, and found the former to be higher than the latter.

Berndt et al. (2008) investigated the variations in the credit risk premium that comprises a major component of the CDS spread for three sectors, namely broadcasting and entertainment, health care, and oil and gas. They found remarkable differences in the spread variations between these sectors. Zhang et al. (2009) used an approach that identifies the volatility and jump risks of individual firms from high frequency stock prices to explain the CDS premium. Their empirical results suggested that the volatility risk alone predicts $48 \%$ of the variation in CDS spread levels, whereas the jump risk alone forecasted $19 \%$. After controlling for credit ratings, macroeconomic conditions, and firm balance sheet information, they predicted $73 \%$ of the total variation. Simulation results suggested that the high frequency-based volatility measures can help explain the credit spreads above and beyond what is already captured by the true leverage ratio.

Another stream of the literature uses structural models to examine CDS spreads as pure measures of credit risk. This literature includes Bharath and Shumway (2008), Blanco et al. (2005), and Ericsson et al. (2009), among others. Bharath and Shumway (2008) examined the accuracy and contribution of the Merton distance to default (DD) model and compared it with a "naïve" alternative which uses the functional form adopted by the Merton model, but does not solve the model for an implied probability of default. The empirical results suggest that the naïve predictor performs slightly better in hazard models and in out-of-sample forecasts than both the Merton DD model and a reduced-form model that uses the same inputs. 
Using a small sample of US and European firms, Blanco et al. (2005) find support for the theoretical arbitrage relationship between CDS prices and credit spreads, on average. When this relationship is violated, the CDS price can be considered as the upper bound for the true credit risk price, while the spread can be viewed as the lower bound. Their results suggest that the common variables used in the literature have greater explanatory power in explaining the changes in credit default swap prices than in the credit spreads. They also suggest that the CDS is the main forum for credit risk price discovery.

Ericsson et al. (2009) investigated the relationship between theory-based determinants of default risk and default swap spreads. They found that only a small set of theoretical determinants of default risk are consistent with theory, and are significant statistically and economically meaningful. Specifically, volatility and leverage have strong explanatory power in univariate and multivariate regressions. A principal component analysis of residuals and spreads indicates limited significance for a residual common factor, confirming that the theory-based variables explain a significant portion of the variation in the data.

Other studies have examined the relationships between equity and credit markets using time series data instead of cross section data, as is the cases discussed above. Bystrom (2006) examines the properties of the Dow Jones iTraxx index, which is an index of CDS securities on 12 European reference entities. He found that CDS spreads are significantly autocorrelated in the seven sectors comprising the iTraxx index, and are also significantly negatively related to the contemporaneous stock returns in all sectors, except for energy, consumers, and financials. 
Fung et al. (2008) studied the relationship between the stock market and high yield and investment grades and the CDS markets in the USA, and found that the lead/lag relationship between them depends on the credit quality of the underlying reference entity. Forte and Lovreta (2008) examined the relationship between company-level CDS and stock marketimplied credit spreads (ICS) in recent years, and found the relationship to be stronger, and the probability that the stock market leads in the price discovery to be higher, at lower credit quality levels. However, the probability of CDS spreads leading in the price discovery rises with increases in the frequency of the severity of credit downturns.

Zhu (2006) discovered a long-run (cointegrating) relationship between credit risk in the corporate bond market and CDS market, although a substantial deviation from the theoretical parity relationship can arise in the short run. The VECM analysis suggests that the deviation is largely due to the higher responsiveness of CDS premia to changes in the credit conditions. Norden and Weber (2009) examined the relationships between CDS, bond and stock markets during the period 2000-2002. They investigated monthly, weekly and daily lead-lag relationships using VAR/VEC models, and found that stock returns lead CDS and bond spread changes. They also found that CDS spread changes Granger-cause bond spread changes for a higher number of firms than the reverse. They contended that the CDS market is more sensitive to the stock market than the bond market, and that this sensitivity increases for the lower credit quality. Finally, they found that the CDS market contributes more to price discovery than the bond market, with this result being stronger for US than for European firms.

On the informational content of the VIX, Luo and Zhang (2010) extended VIX to other maturities and constructed daily VIX term structure data, proposing a simple two-factor 
stochastic volatility framework for VIX. Their results indicate that the framework captures both the time series dynamics of VIX and the rich cross-sectional shape of the term structure. Consistent with previous studies, it was found that VIX contains more information than historical volatility.

Becker et al. (2009) examined two issues relating to the informational content of the VIX implied volatility index. One relates to whether it subsumes information on how historical jump activity contributed to the price volatility, and the other one pertains to whether VIX reflects any incremental information pertaining to future jump activity relative to modelbased forecasts. It is found that VIX both subsumes information relating to past jump contributions to total volatility and reflects incremental information relevant to future jumps.

In a related study, Figuerola-Ferretti, and Paraskevopoulos (2010) considered the cointegration and lead in the price discovery process between credit risk, as represented by CDS spreads, and market risk embedded in the equity VIX. They found that CDS and VIX are cointergated and that VIX has a clear lead over the CDS market in the price discovery process, implying that CDS adjusts to market risk when there is temporary mispricing from the long-run equilibrium. They found that there are long-term arbitrage relationships between VIX and CDS for most companies, implying that excess returns may be earned using "pairs trading" strategies.

Forte and Peña (2009) explore the dynamic relationship between stock market implied credit spreads, CDS spreads and bond spreads. Using a sample of North American and European firms, and using VECM, the empirical results on price discovery indicate that stocks lead CDS and bonds more frequently than the reverse. It also confirms the leading role of CDS with respect to bonds. 
Fernandes et al. (2009) examined the time series properties of daily VIX. Their results suggest that VIX displays long-range dependence. They confirm the evidence in the literature that there is a strong negative relationship between VIX and S\&P500 index returns, as well as a positive contemporaneous link with the volume of the S\&P500 index. Moreover, they demonstrated that VIX tends to decline as the long-run oil price increases, reflecting the high demand from oil in recent years, as well as the recent trend of shorting energy prices in the hedge fund industry.

In contrast to the above, and given the pivotal importance of oil in the modern economy, we will examine the third-party credit risk embedded in the oil-related sectors, and relate that to types of market risk, such the expected option volatility in the stock and credit markets. Such an analysis will enable an examination of the migration of risk in the different sectors and markets at a time of volatile oil prices. The near bankruptcy of GM attests to the importance of such a risk-related examination. We will also determine the dynamic relationships between these markets in the post 2007-2008 financial crisis subperiod. Thus, our approach will examine forcing-dependent variable relationships at the sector level, in contrast to the previous literature, which has focused on the firm level. This will be of substantial interest to energy regulators, policy-makers and investors in the energy-related sectors.

\section{Methodology and Empirical Results}

Let $X_{t}$ denote a $p$-dimensional column of $I(1)$ variables, which follows the following $\operatorname{VAR}(k)$ process: 


$$
X_{t}=A_{1} X_{t-1}+A_{1} X_{t-2} \ldots+A_{1} X_{t-k}+\mu+\varepsilon_{t}
$$

where $\mu$ is a deterministic term, $k$ is the order of lag length, and $\varepsilon_{t}$ is a Gaussian error term. ${ }^{5}$ The $\operatorname{VAR}(k)$ process can be written in the following VECM representation:

$$
\Delta X_{t}=\Pi X_{t-1}+\sum_{i=1}^{k-1} \Gamma_{i} \Delta X_{t-i}+\mu+\varepsilon_{t}
$$

where $\Pi$ and $\Gamma_{i}$ are $p x p$ matrices of coefficients representing the long-run impacts and the short-run adjustments, respectively. The matrix, $\Gamma_{i}$, represents the interim multipliers. The hypothesis of cointegration states that the long-run impact matrix, $\Pi$, can be rewritten as:

$$
\Pi=\alpha \beta^{\prime}
$$

where $\alpha$ and $\beta$ are pxr matrices. The row of matrix $\alpha$ forms the cointegrating vectors, while matrix $\beta$ contains the loading factors which are the weights of the cointegrating vectors in the various equations. These matrices are of full rank, $r$, such that $0 \leq r \leq p-1$, given $X_{t}$ is a $I(1)$ process. If $r=0$, then no cointegration relationship exists among the elements of $X_{t}$. If the rank $r$ is such that $0 \leq r \leq p-1$, then $r$ cointegrating vectors exist, namely $r$ stationary linear combinations of the elements of $X_{t}$ exist with $p-r$ common stochastic trends.

We use the Johansen (1995) method to test the rank of the impact matrix, П. We can also perform the Granger-causality test based on equation (2). If all $\Gamma_{i}(m, n)$ are jointly not equal to zero, then the $n$th variable in vector $X$ is said to Granger-cause the $m$ th variable.

\footnotetext{
${ }^{5}$ A deterministic time trend can also be included.
} 
Otherwise, the $n$th variable does not Granger-cause the $m$ th variable. The joint significance can be tested by various methods such as F, Wald or LR tests.

In this paper, the possibly maximum VAR dimension $p$ is seven, representing the four oil-related CDS sector indexes, oil futures price, VIX and MOVE/SMOVE index. We will include SMOVE and exclude MOVE in the two VAR systems as the correlation between MOVE and SMOVE is very high, the systems that include SMOVE satisfy the diagnostic tests more strongly than those that include MOVE, and SMOVE involves floating interest rates that carry risk while all Treasury yields that define MOVE are risk free.

\section{Cointegration Tests (full period)}

There are many tests for detecting cointegration, the most general being the multivariate tests based on the autoregressive representation, as discussed in Johansen (1988), and Johansen and Juselius (1990). As is well known, the Johansen maximum likelihood method provides two different likelihood ratio tests, namely the trace and maximum eigenvalue tests, to determine the number of cointegrating vectors over the full period and the 2009 Recovery subperiod. We will also use both the Akaike Information Criterion (AIC) and the Schwartz Bayesian Criterion (SBC) to determine the VAR and cointegration specifications, as well as the lag lengths.

We will examine cointegration for two systems. System I is the seven-variable system, which includes the non-risk variable oil futures price, while System II contains the six riskmeasuring variables only, and excludes the oil price. We will investigate System II under the full sample period and under the subsample July 1, 2009 - January 21, 2011, which marks 
economic recovery in the USA following the 2007-2008 Great Recession that ended in June 2009.

As indicated above, both systems include SMOVE instead of MOVE. Interestingly, Johansen's cointegration tests suggest that under all five possible cointegration and VAR specifications, System I for the full sample has one cointegrating vector, while System II has two cointegrating vectors, according to both the trace and maximum eigenvalue tests (Table 3 - Panels A and B). The oil price does not measure risk and the four oil-related CDS sector indexes, which incorporate default and liquidity components, are significantly different from the VIX and SMOVE indexes, which assimilate expected volatility components. These facts should confirm the results that the cointegration relationships for these two systems should be different.

\section{[Table 3 goes here]}

In this paper, which concentrates on risk measures, we will focus on System II that does not include the oil price. As indicated above, this system has two long-run equilibrium relationships among its six indexes over the whole sample (Tables 4 and 5). This finding implies that there are four common stochastic trends that co-move the four CDS indexes, SMOVE and VIX, making System II more stable than System I. Specification 2 of the intercept and no trend in the cointegrating and VAR specifications gives the best fit of all five specifications under the full sample, according to both AIC and SBC.

\section{[Tables 4 and 5 go here]}

All the drivers in both two long-run equilibrium (cointegrating) relationships for the oil and gas CDS index and the utility CDS index are significant in System II. This suggests that 
these indexes drive adjustments to the long-run equilibrium in the associated VEC as they process new information or reflect new risk events (Table 6). ${ }^{6}$ In the first cointegrating equation, with the oil and gas CDS index placed on the left-hand side of the first long-run relationship, the auto CDS index, VIX and SMOVE have positive signs on the right-hand side of the relationship. This finding suggests that rising risk in the auto sector (arising from, for example, the bankruptcy of GM), the stock market and interest rate swap options market increases the insurance protection premium in the auto sector. However, the chemical CDS index in that relationship has a surprisingly negative sign when placed on the right-hand side of the equation, implying that protection risk in the chemical sector moves in a different direction from the same risk in the auto sector. This might arise because oil and natural gas are the basic ingredients in the chemical sector, which benefits from lower oil prices. Chemicals and oil prices usually have negative correlations.

\section{[Table 6 goes here]}

The second cointegrating relationship, which has the utility CDS index on the left-hand side, has similar characteristics to the first equation. In summary, protection and expected volatility risks can migrate between the different oil-related sectors, and from and the stock and interest rate swap options markets. The highest impacts come from VIX, followed by SMOVE and the chemical sector CDS index.

Vector Error Correction Models (full period)

\footnotetext{
${ }^{6}$ If the CDS index of the chemical sector is ordered among the first two variables in the system, it will not respond to drivers such as the utility CDS index and SMOVE.
} 
The estimation of the six-risk variable VEC model for System II under the full sample, which has two long-run (cointegrating) relationships, demonstrates significance for almost all error-correction terms (Table 7). This means that the ECT terms are error correcting in the adjustment to the long-run equilibrium, and that for the auto CDS demonstrates the largest error correction. Exceptions are the ECTs for the utility CDS indexes, which are not error correcting to either of the two ECTs in the long run, perhaps because this sector is highly regulated and represents a natural monopoly, as indicated above. These characteristics might have impacted this sector's CDS spread response to the long run drivers. The chemical CDS index also does not no error correct to the adjustment arising from only the first long-run equilibrium relationship.

\section{[Table 7 goes here]}

Based on the significance and sizes of the two ECTs, or speeds of adjustments for the six risk spreads, the auto CDS spread has the highest size for both ECTs. The auto CDS spread leads in the price discovery of risk in the long run. The VIS spread has a slightly lower speed of adjustment than the auto CDS spread, which makes it a close runner-up in this complex of risk.

Regarding the sensitivity in the short run, the oil and gas CDS spread is responsive to changes in almost all of the variables, with the exception of SMOVE. The exception could hold because oil and gas companies do not deal with interest rate swaps, which are based mainly on bonds, consumer loans and mortgages, which are reflected in SMOVE. The sensitivity of the utility CDS spread excludes the changes in the chemical CDS and 
SMOVE. ${ }^{7}$ The auto CDS spread is less sensitive than the oil and gas CD spread, but has a similar sensitivity to the utility CDS spread, showing particular short-run adjustments to changes in its own CDS spread, utility CDS and the VIX spread. The chemical CDS spread demonstrates the least responsiveness to the adjustment in the other variables in the short run, with its adjustment being to itself and VIX.

It is worth noting that SMOVE is responsive to changes in the auto CDS spread, probably because SMOVE reflects options written on auto loans. In summary, in the short run, oil and gas CDS spread demonstrates the greatest adjustments, while the chemical CDS shows the least adjustments. All four oil-related CDS indexes are responsive to VIX in the short run, but none is sensitive to SMOVE, which receives risk unilaterally from VIX.

\section{Exogeneity Restrictions (full period)}

The cointegration and short- and long-run results are also confirmed by the long-run, weak exogenity and block exogeneity tests (Urbain, 1992) (Table 8). The test results of the longrun Granger-(non)causality hypothesis is rejected for all the variables, with the exception of SMOVE, which does not show strong adjustments in the long run. This test indicates that there is long-run Granger-causality because almost all the endogenous variables adjust to the deviations from the long-run equilibrium. The weak exogeneity test also suggests that each of the six variables in the system plays a significant role in the long-run equilibrium, given that the beta parameters are not equal to zero in the VECM system.

\section{[Table 8 goes here]}

\footnotetext{
${ }^{7}$ This result also holds for the system with MOVE.
} 
The results for the multivariable block exogeneity Wald test derived from the VEC model, which examines the additional causal relationship between each dependent variable of the six variables in System II and the lagged endogenous variables in the VEC equation, are also significant. The null hypothesis in this case is that the lagged endogenous variables do not Granger-cause the dependent variable. The null hypothesis is rejected, which is to be expected, given that more than the lagged endogenous variable is significant. Such an outcome shows that this model will be superior to the naïve model.

\section{Generalized Variance Decomposition (full period)}

The previous analysis concentrated on the long-run equilibrium relationships and the causal explanatory power among the variables. The short-run relationships deserve further attention because more information can be obtained from examining the relationships among all the variables in the short run. We concentrate on the relative importance of a shock in any of the six variables in the individual forecast error variances of all those variables in System II for the full period. This should provide the market participants, who are shock-averse, with the required information to recognize the relative importance of shocks and to use adequate financial instruments to benefit from them in the short run.

The results over a 50-day horizon are reported in Table 9. They suggest that the relative importance of an own shock in any of the variables in the individual forecast error variance of all the variables is more than $45 \%$, but with varying degrees. SMOVE has the highest weight for the own shock among all the variables, reaching $89 \%$, while the utility CDS index touches $45 \%$. It is interesting to note that the weight of VIX in the oil and gas CDS forecast error variance is about 
$30 \%$, while the weight of the oil and gas CDS in the standard error variance of the utility CDS is $39 \%$. Oil and CDS account for $20 \%$ of the standard error variance of VIX, emphasizing the importance of fluctuations in oil and gas prices and in energy stocks.

\section{[Table 9 goes here]}

Impulse Response Analysis

We also examined several possible orderings to perform the orthogonal impulse response function (IRF) analysis for the six-risk variable in System II, and found sensitivity to the orderings. However, Koop et al. (1996) and Pesaran and Shin (1998) developed the generalized IRF that is not sensitive to the ordering of the variables in the VAR. In addition, the generalized IRF is able to capture immediate responses of endogenous variables to shocks, which is advantageous when analyzing markets where information is assimilated quickly. Thus, we performed the generalized IRF analysis with $95 \%$ confidence bands.

The results of the impulse response analysis for the four oil-related sector CDS spreads show the strongest response is to own sector shock and VIX (that is, expected equity volatility), which confirm the results of the VEC model. For all of these CDS sector indexes, the response to the shock from the chemical sector declines over time.

The responses to the oil and gas CDS spread to the other shocks increase for most of the shocks over the 50-period horizon, with the shock to VIX having the highest value, followed by its own shock and that of the utility CDS spread. Most of the responses of the utility CDS spread 
come from their own, followed by VIX and the oil and gas CDS spread. The response to the chemical CDS declined over the horizon, as is the case for the oil and gas CDS.

The auto CDS spread receives the strongest shock from its own, followed by shocks from VIX. The response to utility CDS is third, as is the case for the other non utility sectors. Interestingly, the chemical CDS spread responds the most to VIX, more than to its own shock. Its response to shocks for the other sectors is almost even.

Somewhat strangely, the response of SMOVE to VIX decreases over the horizon, but it shows greater sensitivity to the auto CDS. This is perhaps due to the fact that some interest rate options are written on auto loans. Finally as expected, most of the response of VIX is to its own shock that is related to expected volatility in the stock market. The second highest response of VIX is to the shock emanating from the oil and gas CDS. Oil prices are highly volatile, and energy stock capitalization is among the highest in the S\&P 500 index.

\section{Cointegration Tests (Recovery Subperiod)}

As indicated above, this subperiod follows the Great Recession, which started in the USA in December 2007 and ended in June 2009. The economic recovery period starts from July 2009 and continues until the end of our sample, January 21, 2011. The two cointegration procedures, namely the trace and the maximum eigenvalue tests, show that the six-risk variable System II under the economic recovery subperiod has only one long-run equilibrium relationship among the variables, compared with two under the full period (see Table 10 and Table 4 - Panel C). This result implies that there are five common stochastic shocks that co-move this system in the subperiod, which suggests that System II has become relatively easier to model and interpret 
after the US economic sectors and markets underwent adjustments during the 2007-2008 Great Recession.

Interestingly, VIX and SMOVE do not error correct to the long-run equilibrium in this subperiod (the results are available from the authors on request). This outcome is likely to be due to the damage caused by the global financial crisis to the credit and stock markets. Moreover, the oil and gas CDS spread, which actively adjusts in the long run under the full period, shows no significance in the recovery period. Such an outcome may be due to the collapse of oil prices and the inertia in the natural gas prices as a result of the increases in shale gas reserves. Surprisingly, the chemical CDS spread error corrects in the long run, possibly because of the drastic fall in oil prices during the Great Recession.

\section{[Table 10 goes here]}

In the short run, the adjustments are also much less in the subperiod than in the full period. SMOVE does not adjust to VIX, as do the oil and gas CDS and auto CDS indexes. However, the chemical CDS spread adjusts in the short run, which is contrary to the full period.

\section{Conclusions}

Given the increased risk in oil prices, the US oil and transportation sectors and high volatility in the US equity and credit markets, this paper examined the interrelations among six different measures of risk in four oil-related sectors and equity and bond/ interest rate options markets during the period January 1, 2004 - January 21, 2011, and also in the economic recovery July 1, 2009 - January 21, 2011 subperiod that followed the 2007-2008 Great Recession. The risk 
in the oil-related sectors is represented by insurance protection CDS spreads or premiums, which incorporate liquidity and default risk components, while the risk in the equity and interest rate options markets are captured by the expected volatility risk.

The overall results demonstrate that these six different measures of risk have only two long-run equilibrium relationships in the full period, and only one such relationship in the recovery subperiod. Moreover, the long- and short-run adjustments appear to have weakened in the subperiod, suggesting that there is greater "localization" of risk in their own sectors. It seems that this complex of risk has less co-movement and interrelationships among the different measures in the recovery period after dealing with from the subprime real estate crisis and the commodity and stock market bubbles, particularly in the long run. This is an important result for the future of the economy and its financial markets, particularly in the oil-related sectors.

The auto sector had the highest speed of risk adjustments in the long run, and was a leader of risk transmission in the short run. This result suggests that policy makers should give special attention to risk in this sector. Based on this finding, the bailout of the auto companies after the Great Recession was quite possibly the correct decision. Interestingly, the risk in the chemical sector, which uses oil and natural gas as feedstock, seems to co-move inversely with the risk in the oil and other oil-related sectors.

It seems that the equity market is a common and consistent source of risk for all the oilrelated sectors and the bond/ interest rate options markets, particularly for the full period. The important policy implication is that regulatory authorities (such as the Fed and SEC) should be aware of this result when policy comes to transmission and migration of risk to the CDS sector market. 


\section{References}

Abid, F. and Naifar, N. 2006. Credit-default swap rates and equity volatility: A nonlinear relationship, Journal of Risk Finance 7, 348-371.

Acharya, V.V. and Johnson, T.C. 2007. Insider trading in credit derivatives. Journal of Financial Economics 84, 110-141.

Becker, R. Clements, A. E. and McClelland, A. 2009. The jump component of S\&P 500 volatility and the VIX index. Journal of Banking and Finance 33 (6), 1033-1038.

Berndt, A., Douglas, R., Duffie, D., Ferguson, M. and Schranz, D. 2008. Measuring default risk premium from default swap rates and EDFs. BIS Working Paper No. 173. EFA 2004 Maastricht Meetings Paper No. 5121.

http://www.andrew.cmu.edu/user/aberndt/Beetal08.pdf.

Bharath, S. and Shumway, T. 2008. Forecasting default with the KMV-Merton model. Journal of Financial Studies 21, 1339-1369.

Blanco, R., Brennan, S., and Marsh, I.W. 2005. An empirical analysis of the dynamic relationship between investment-grade bonds and credit default swaps. Journal of Finance $60,2255-2281$.

Bystrom, H. 2006. Credit default swaps and equity prices: The iTraxx CDS index market. Financial Analysts Journal 62, 65-76.

Chan, K. 1993. Consistency and limiting distribution of the least squares estimator of a threshold autoregressive model. Annals of Statistics 21, 520-533

Das, S.R. and Hanouna, P. 2006. Credit default swap spreads. Journal of Investment Management 4, 93-105.

Dickey, D.A. and Fuller, W.A. 1979. Distribution of the estimators for autoregressive time series with a unit root. Journal of the American Statistical Society 75, 427-431. 
Duffie, D. and Singleton, K.J. 1999. Modeling term structures of defaultable bonds. The Review of Financial Studies 12, 687-720.

Emmons, W. and Schmid, F. 2004. Monetary policy actions and the incentive to invest. Business Economics 39(2), 24-29 Also available as Working Paper 2004-018A, Federal Reserve Bank of St. Louis, St. Louis, MO.

https://research.stlouisfed.org/wp/view/author/64/0/1/

Engle, R. and Granger, C. 1987. Cointegration and error-correction representation, estimation and testing. Econometrica 55, 251-2.

Ericsson, J., Jacobs, K., and Oviedo-Helfenberger, R. 2009. The determinants of credit default swap premia. Journal of Financial and Quantitative Analysis 44, 109-132.

Ericsson, J., Reneby, J., and Wang, H. 2006. Can structural models price default risk? Evidence from bond and credit derivative markets." Working Paper, McGill University. http://w4.stern.nyu.edu/salomon/docs/Credit2006/EricssonRenebyWang.pdf

Fernandes, M., Medeiros, M.C. and Scharth, M. 2009. Modeling and predicting the CBOE market volatility index. http://webspace.qmul.ac.uk/mfernandes/Papers/Vix.pdf.

Figuerola-Ferretti, I. and Paraskevopoulos, I. 2010. Pairing market with credit risk. Available at SSRN: http://ssrn.com/abstract=1553863.

Forte, S. and Lovreta, L. 2008. Credit risk discovery in the stock and CDS markets: Who, when and why leads.

http://www.efmaefm.org/OEFMAMEETINGS/EFMA\%20ANNUAL\%20MEETINGS/2008athens/Lovreta.pdf

Forte, S. and Peña, J.I. 2009. Credit spreads: An empirical analysis on the informational content of stocks, bonds, and CDS. Journal of Banking and Finance 33, 2013-2025 
Fung, H.G., Sierra, G.E., Yau, J., and Zhang, G. 2008. Are the U.S. stock market and credit default swap market related? Evidence from the CDX Indices Journal of Alternative Investments 11, 43-61.

Greatrex, C. 2008. The credit default swap market's determinants, efficiency and relationship to the stock market. ETD Collection for Fordham University. Paper AAI3301438. http://fordham.bepress.com/dissertations/AAI3301438.

Johansen, S. 1988. Statistical analysis of cointegrating vectors. Journal of Economic Dynamics and Control. 12, 231-254.

Johansen, S. and Juselius, K. 1990. Maximum likelihood estimation and inferences on cointegration-with application to demand for money. Oxford Bulletin of Economics and Statistics 52, 169-210.

Koop, G., Pesaran, M. and Potter, S,M. 1996. Impulse response analysis in nonlinear multivariate models. Journal of Econometrics 74, 119-147

Kucuk, U.N. 2010. Non-default component of sovereign emerging market yield spreads and its determinants: Evidence from credit default swap market. Journal of Fixed Income. [???]

Longstaff, F., Mithal, S., and Neis, E. 2005. Corporate yield spreads: default Risk or liquidity? New evidence from the credit default swaps market. Journal of Finance 60, 22132253.

Luo, X. and Zhang, J.E. 2010. The term structure of VIX. http://hdl.handle.net/10722/127838.

Miller, M., Weller, P., and Zhang, L. 2002. Moral hazard and the US stock market: Analyzing the 'Greenspan Put'. Economic Journal 112 (478), C171-C186.

$\mathrm{Ng}$, S. and Perron, P. 1995. Unit root tests in ARMA models with data dependent methods for truncation lag. Journal of the American Statistical Association, 429, 268-281.

Norden, L. and Weber, M. 2009. The co-movement of credit default swap, bond and stock markets: An empirical analysis. European Financial Management 15, 529-562. 
Norden, L and Weber, M. 2004. Informational efficiency of credit default swaps and stock market. Journal of Banking and Finance 28, 2813-2843. Also available as Discussion Paper DP 4250, Center for Economic Policy Research. London, United Kingdom. www.cepr.org/pubs/dps/DP4250.asp.

Pesaran, H. and Shin, Y. 1998. Generalized impulse response analysis in linear multivariate models. Economics Letters 58, 17-29.

Phillips, P.C.B. and Perron, P. 1988. Testing for a unit root in time series regressions. Biometrica 75, 335-346.

Raunig, B. and Scheicher, M. 2009. Are the banks different? Evidence from CDS market. BIS https://www.bis.org/bcbs/events/cbrworkshop09/raunigscheicher.pdf.

Urbain, J.P. 1992. On weak exogeneity in error-correction models. Oxford Bulletin of Economics and Statistics 54 (2), 187-207.

Wingfield, B. 2010. The end of the Great Recession? Hardly. Business in the Beltway. http://blogs.forbes.com/brianwingfield/2010/09/20/the-end-of-the-great-recessionhardly/?boxes=businesschannelsections

Zhang, B., Zhou H. and Zhu, H. 2009. Explaining credit default swap spreads with the equity volatility and jump risks of individual firms. Review of Financial Studies, 22(12) 5099-5131.

Zhu, H. 2006. An empirical comparison of credit spreads between the bond market and the credit default swap market. Journal of Financial Services Research 29, 211-235. 
Table 1: Descriptive Statistics (full period)

Panel A: Levels

\begin{tabular}{|c|c|c|c|c|c|c|c|c|}
\hline & \multicolumn{4}{|c|}{ CDS_AUTOCDS_CHEMCDS_OILGACDS_UTIL } & MOVE & OIL_PRIC & SMOVE & SP_VIX \\
\hline Mean & 6.177634 & 4.737999 & 4.642684 & 4.859333 & & 0.458167 & & 2.929088 \\
\hline Median & 6.04 & 4.62 & 4.5 & 4.750 & 526127 & 0.477 & 7006 & 2.860485 \\
\hline Maximum & $9.0^{\circ}$ & & & & & & & 719 \\
\hline Minimum & 4.939497 & 3.803960 & 3.760 & 3.653723 & 3.935740 & -0.296931 & 3.998934 & 2.291524 \\
\hline Std. Dev. & 0.8 & 0.66 & 0.56 & 0.60 & 0.32 & 0.30 & 789 & 0.424777 \\
\hline C.V. & 0.138874 & 0.140817 & 0.12116 & 0.124068 & 0.070979 & 0.671225 & 835 & 0.14502 \\
\hline Skewness & 1.328446 & 1.830563 & 0.4872 & 0.271974 & 0.481751 & -0.134256 & 7750 & 0.864953 \\
\hline Kurtosis & 4.508491 & 7.007191 & 2.172830 & 1.910314 & 2.723003 & 3.020406 & 2.771115 & 3.403074 \\
\hline Jarque-Bera & 716.4323 & 2261.164 & 125.4479 & 113.8428 & 77.13856 & 5.565540 & 102.9793 & 242.1496 \\
\hline Probability & 0.000000 & 0.000000 & 0.000000 & 0.000000 & 0.000000 & 0.061867 & 0.000000 & 0.000000 \\
\hline Observations & 1842 & 1842 & 1842 & 1842 & 1842 & 1842 & 1842 & 1842 \\
\hline
\end{tabular}

Panel B: Return

\begin{tabular}{|c|c|c|c|c|c|c|c|}
\hline & \multicolumn{7}{|c|}{ DCDS_AUTODCDS_CHEMDCDS_OILGADCDS_UTIL DMOVE DOIL_PRICDSMOVEDSP_VIX } \\
\hline Mean & 0.000144 & 0.000146 & 0.000406 & 0.000497 & -0.000119 & 0.000577 & $-0.0001304 .73 \mathrm{E}-06$ \\
\hline Median & & & & & & & 003592 \\
\hline & & & & & & & 496008 \\
\hline & & & & & & 315 & 0588 \\
\hline Std. I & & & & & & 0.022040 & 064194 \\
\hline $\mathrm{Sk}$ & -7.902 & -4.48 & 0.67 & 0.590542 & 207 & -0.141444 & $\begin{array}{lll}0.438743 & 0.634740\end{array}$ \\
\hline Kurtosis & 205.9458 & 196.6863 & 43.10651 & 9.427756 & 7.495324 & 5.713115 & 7.7505227 .818432 \\
\hline Jarqu & 3178 & & & & & & $1790.176 \quad 1904.581$ \\
\hline Probability & 0.000000 & 0.000000 & 0.000000 & 0.000000 & 0.000000 & 0.000000 & $0.000000 \quad 0.000000$ \\
\hline
\end{tabular}

Notes: All variables are expressed in natural logarithms of the levels for Panel A and log difference for panel B. The coefficient of variation (C.V.) is the ratio of the standard deviation to the mean. CDS_AUTO is the US CDS spread sector index for the auto sector; CDS_CHEM is the US CDS spread sector index for the chemicals sector; CDS_OILGA is the US CDS spread sector index for the oil \& gas sector; OIL_PRIC is the daily closing price for the crude oil futures contract 3 (dollars per gallon) delivered in Cushing, OK; and $S P_{-} V I X$ is the CBOE SPX volatility VIX (NEW) - price index; MOVE is the one- month bond volatility index; and $S M O V E$ is the one-month volatility index for swaption. The full period is January 1 , 2004-January 21, 2011. 
Table 2: Correlation Matrix for Levels and Returns (full period)

\section{Panel A: Levels}

\begin{tabular}{|c|c|c|c|c|c|c|c|c|}
\hline Correlations & CDS_AUTO & CDS_CHEM & CDS_OIGA & CDS_UTIL & MOVE & Oil_PRIC & SMOVE & $S P_{-} V I X$ \\
\hline CDS_AUTO & 1.00000 & & & & & & & \\
\hline CDS_CHEM & 0.84086 & 1.00000 & & & & & & \\
\hline CDS_OILGA & 0.69260 & 0.85120 & 1.00000 & & & & & \\
\hline CDS_UTIL & 0.6533 & 0.78930 & 0.97462 & 1.00000 & & & & \\
\hline MOVE & 0.61715 & 0.77313 & 0.7508 & 0.72574 & 1.00000 & & & \\
\hline$O I L \_P R I C$ & 0.25530 & 0.07533 & 0.13308 & 0.10689 & 0.125949 & 1.0000 & & \\
\hline SMOVE & 0.63021 & 0.77048 & 0.74926 & 0.73053 & 0.98499 & 0.10471 & 1.00000 & \\
\hline$S P_{-} V I X$ & 0.77113 & 0.87374 & 0.87869 & 0.82653 & 0.82784 & 0.18831 & 0.79977 & 1.00000 \\
\hline
\end{tabular}

\section{Pane A: Returns}

\begin{tabular}{|c|c|c|c|c|c|c|c|}
\hline \multirow{3}{*}{$\begin{array}{l}\text { Correlations } \\
D C D S \_A U T \\
D C D S \text { CHE }\end{array}$} & \multicolumn{7}{|c|}{$\begin{array}{l}\text { DCDS_AUT DCDS_CHEM DCDS_OILGA DCDS_UTIL DMOVE DOIL_PRIC DSMOVE DSP_VIX } \\
O\end{array}$} \\
\hline & 1.00000 & & & & & & \\
\hline & & & & & & & \\
\hline$M$ & 0.12732 & 1.00000 & & & & & \\
\hline$D C D S \_O I L G$ & 0.32102 & 0.24914 & 1.00000 & & & & \\
\hline$D C D S \_U T I L$ & 0.33560 & 0.28612 & 0.65923 & 1.00000 & & & \\
\hline DMOVE & 0.04368 & 0.07084 & 0.12342 & 0.148891 .00000 & & & \\
\hline DOIL_PRIC & -0.11359 & -0.03494 & -0.16874 & $-0.18861-0.05096$ & 1.00000 & & \\
\hline DSMOVE & 0.04513 & 0.06893 & 0.12398 & 0.158750 .81579 & -0.07096 & 1.00000 & \\
\hline$D S P \_V I X$ & 0.19129 & 0.09219 & 0.23856 & $0.23788 \quad 0.18525$ & -0.19672 & 0.22432 & 1.00000 \\
\hline
\end{tabular}

Notes: All variables are expressed in natural logarithms of the levels for Panel A and log difference for panel B. The coefficient of variation (C.V.) is the standard deviation to the mean. CDS_AUTO is the US CDS spread sector index for the auto sector; CDS_CHEM is the US CDS spread sector index for the chemicals sector; CDS_OILGA is the US CDS spread sector index for the oil \& gas sector; OIL_PRIC is the daily closing price for the crude oil futures contract 3 (dollars per gallon) delivered in Cushing, OK; and SP_VIX is the CBOE SPX volatility VIX (NEW) - price index; MOVE is the one- month bond volatility index; and SMOVE is the one-month volatility index for swaption. The full period is January 1 , 2004-January 21, 2011. 
Table 3: Unit Root Tests (full period)

\begin{tabular}{|c|c|c|c|c|}
\hline Levels & $\begin{array}{l}\text { ADF (constant) } \\
\text { t-statistic }\end{array}$ & $\begin{array}{l}\text { ADF (const \& } \\
\text { trend) } \\
\text { t-statistic }\end{array}$ & $\begin{array}{l}\text { PP (constant) } \\
\text { Adj. t-statistic }\end{array}$ & $\begin{array}{l}\mathrm{PP}(\text { const \& trend }) \\
\text { Adj. t-statistic }\end{array}$ \\
\hline CDS_AUTO & -1.609798 & -1.051821 & -1.735014 & -1.511779 \\
\hline CDS_CHEM & -1.323433 & -1.366534 & -1.706130 & -1.894390 \\
\hline CDS_OILGA & -1.312602 & -1.729808 & -1.308393 & -1.669351 \\
\hline CDS_UTIL & -0.917851 & -1.563846 & -0.988033 & -1.699290 \\
\hline OIL_PRIC & -2.287116 & -2.347307 & -2.260227 & -2.294210 \\
\hline MOVE & -2.509701 & -2.748824 & -2.471671 & -2.746934 \\
\hline SMOVE & -2.783388 & -3.033995 & -2.384573 & -2.627608 \\
\hline SP_VIX & -2.614858 & -3.248820 & -2.585638 & -3.405480 \\
\hline & $\begin{array}{c}1 \% \text { level }-3.433724 \\
5 \% \text { level }-2.862917 \\
10 \% \text { level }-2.567550\end{array}$ & $\begin{array}{c}1 \% \text { level }-3.963068 \\
5 \% \text { level }-3.412267 \\
10 \% \text { level }-3.128065\end{array}$ & $\begin{array}{c}1 \% \text { level }-3.433701 \\
5 \% \text { level }-2.862907 \\
10 \% \text { level }-2.567544\end{array}$ & $\begin{array}{c}1 \% \text { level }-3.963035 \\
5 \% \text { level }-3.412251 \\
10 \% \text { level }-3.128055\end{array}$ \\
\hline First difference & $\begin{array}{l}\text { ADF (constant) } \\
\text { t-statistic }\end{array}$ & $\begin{array}{l}\text { ADF (cons \& } \\
\text { trend) } \\
\text { t-statistic }\end{array}$ & $\begin{array}{l}\text { PP (constant) } \\
\text { Adj. t-statistic }\end{array}$ & $\begin{array}{l}\mathrm{PP}(\text { cons \& trend }) \\
\text { Adj. t-statistic }\end{array}$ \\
\hline CDS_AUTO & -15.11209 & -15.17437 & -35.60763 & -35.61610 \\
\hline CDS_CHEM & -12.87392 & -12.87395 & -40.44335 & -40.43268 \\
\hline CDS_OILGA & -22.02235 & -22.01664 & -33.98031 & -33.97301 \\
\hline CDS__UTIL & -32.38672 & -32.38086 & -33.05977 & -33.04981 \\
\hline OIL_PRIC & -45.22243 & -45.22482 & -45.20802 & -45.21201 \\
\hline MOVE & -27.53884 & -27.53166 & -41.48660 & -41.47731 \\
\hline SMOVE & -39.78622 & -39.77598 & -40.12973 & -40.11876 \\
\hline SP_VIX & -35.52866 & -35.51908 & -52.37522 & -52.35945 \\
\hline
\end{tabular}

Notes: The variables are expressed in logarithms, while the first difference is the log difference. 
Table 4: Number of Possible Cointegrating Relationships

Panel A: System I (full period with oil price)

\begin{tabular}{llllll}
\hline Data Trend: & None & None & Linear & Linear & Quadratic \\
Test Type: & No Intercept & Intercept & Intercept & Intercept & $\begin{array}{l}\text { Intercept } \\
\text { Trend }\end{array}$ \\
& No Trend & No Trend & No Trend & Trend & Trend \\
\hline Trace & 1 & $1^{*}$ & 1 & 1 & 1 \\
Max-Eig & 1 & $1^{*}$ & 1 & 1 & 1 \\
\hline
\end{tabular}

Panel B: System II (full period without oil price)

\begin{tabular}{llllll}
\hline Data Trend: & None & None & Linear & Linear & Quadratic \\
Test Type: & No Intercept & Intercept & Intercept & Intercept & Intercept \\
& No Trend & No Trend & No Trend & Trend & Trend \\
\hline Trace & 1 & $2^{*}$ & 2 & 1 & 2 \\
Max-Eig & 1 & $2^{*}$ & 2 & 2 & 2 \\
\hline
\end{tabular}

Panel C: System II (subperiod without oil price)

\begin{tabular}{llllll}
\hline Data Trend: & None & None & Linear & Linear & Quadratic \\
Test Type: & No Intercept & Intercept & Intercept & Intercept & Intercept \\
& No Trend & No Trend & No Trend & Trend & Trend \\
\hline Trace & 2 & $1^{*}$ & 1 & 1 & 1 \\
Max-Eig & 1 & $1^{*}$ & 1 & 1 & 1 \\
\hline
\end{tabular}

Notes: VAR System I includes the four CDS sector indexes, oil_PRIC, SMOVE and S\&P_VIX. VAR System II excludes the oil price only. The SMOVE validates diagnostic tests better than MOVE and its SWAP floating interest rate contains risk, in contrast to the Treasury yields for MOVE. Cointegration tests are based on lags of length 3. The full period is January 1, 2004-January 21, 2011 and the subperiod is 7/01/2009-1/21/2011. * indicates the best selection based on both the AIC and SBC information criteria. Critical values are based on MacKinnon-HaugMichelis (1999). 
Table 5: Cointegration Equation for System I (full period)

\begin{tabular}{cc}
\hline Cointegrating Eq: & CointEq1 \\
\hline CDS_AUTO(-1) & 1.000000 \\
CDS_CHEM(-1) & $-9.943068^{\mathrm{a}}$ \\
& {$[-5.67714]$} \\
CDS_OILGA(-1) & $-11.27968^{\mathrm{b}}$ \\
& {$[-2.21819]$} \\
CDS_UTIL(-1) & 3.918394 \\
& {$[0.99126]$} \\
OIL_PRIC(-1) & $-2.970719^{\mathrm{c}}$ \\
& {$[-1.75917]$} \\
SMOVE(-1) & -0.041354 \\
& {$[-0.01514]$} \\
SP_VIX(-1) & $25.45662^{\mathrm{a}}$ \\
& {$[7.55759]$} \\
C & 1.265657 \\
& {$[0.15012]$} \\
\hline
\end{tabular}

Notes: System I includes the four CDS sector indexes, VIX, SMOVE and the oil price. The numbers in brackets are t-statistics. Superscripts a, b and $\mathrm{c}$ represent significance at the $1 \%, 5 \%$ and $10 \%$ levels respectively. The cointegrating equations can be written by changing the signs of the variables on the right-hand side of each equation. The full period is January 1, $2004-$ January 21, 2011. 
Table 6: Cointegration Equations for System II (full period)

\begin{tabular}{ccc}
\hline Cointegrating Eq: & CointEq1 & CointEq2 \\
CDS_OILGA(-1) & 1.000000 & 0.000000 \\
CDS_UTIL(-1) & 0.000000 & 1.000000 \\
CDS_AUTO(-1) & & \\
& -0.656611 & -1.725260 \\
CDS_CHEM(-1) & {$[-1.98394]$} & {$[-2.50938]$} \\
& 3.607673 & 7.857463 \\
SMOVE(-1) & {$[6.13062]$} & {$[6.42761]$} \\
& -1.871838 & -4.803628 \\
SP_VIX(-1) & {$[-2.29651]$} & {$[-2.83700]$} \\
& -4.893549 & -8.058299 \\
C & {$[-5.80311]$} & {$[-4.60014]$} \\
& 5.254517 & 14.27832 \\
\hline
\end{tabular}

Notes: System II does not include the non-risk variable oil price. The variables are logarithms and the numbers in brackets are t-statistics. The cointegrating equations can be written by changing the signs of the variables on the right-hand side of each equation. The full period is January 1, 2004 - January 21, 2011. 
Table 7: VEC for System II (full period)

\begin{tabular}{ccccccc}
\hline Error Correction: & \multicolumn{1}{c}{ D(CDS_OILGA) } & D(CDS_UTIL) & D(CDS_AUTO) $\left(C D S \_C H E M\right)$ & D(SMOVE) & D(SP_VIX) \\
CointEq1 & $-0.008658^{\mathrm{a}}$ & -0.004191 & $-0.031764^{\mathrm{a}}$ & 0.010860 & $-0.009843^{\mathrm{b}}$ & $0.025767^{\mathrm{a}}$ \\
CointEq2 & $0.003201^{\mathrm{c}}$ & 0.001421 & $0.016265^{\mathrm{a}}$ & $-0.007891^{\mathrm{b}}$ & $0.004938^{\mathrm{c}}$ & $-0.011006^{\mathrm{b}}$ \\
D(CDS_OILGA(-1)) & $0.081633^{\mathrm{a}}$ & $0.081308^{\mathrm{a}}$ & 0.006400 & 0.050100 & $-0.078630^{\mathrm{c}}$ & -0.029333 \\
D(CDS_OILGA(-2)) & $-0.181004^{\mathrm{a}}$ & $0.058840^{\mathrm{b}}$ & 0.001049 & 0.060407 & $0.087347^{\mathrm{c}}$ & $-0.148662^{\mathrm{c}}$ \\
D(CDS_UTIL(-1)) & $0.119073^{\mathrm{a}}$ & $0.106165^{\mathrm{a}}$ & 0.123345 & 0.122380 & 0.042042 & $0.171903^{\mathrm{c}}$ \\
D(CDS_UTIL(-2)) & $0.190565^{\mathrm{a}}$ & 0.007033 & $0.149624^{\mathrm{c}}$ & 0.041880 & 0.004157 & 0.043550 \\
D(CDS_AUTO(-1)) & $0.032358^{\mathrm{a}}$ & $0.033509^{\mathrm{a}}$ & $0.161928^{\mathrm{a}}$ & $0.041401^{\mathrm{c}}$ & 0.011159 & 0.012226 \\
D(CDS_AUTO(-2)) & -0.004858 & -0.010557 & $-0.105476^{\mathrm{a}}$ & 0.016255 & $0.035912^{\mathrm{b}}$ & -0.010246 \\
D(CDS_CHEM(-1)) & $0.021456^{\mathrm{c}}$ & 0.010467 & -0.002901 & 0.037436 & -0.008379 & 0.032393 \\
D(CDS_CHEM(-2)) & -0.005163 & -0.006538 & $-0.044195^{\mathrm{c}}$ & $-0.117362^{\mathrm{a}}$ & 0.000337 & -0.011562 \\
D(SMOVE(-1)) & -0.006808 & 0.011571 & 0.034396 & -0.021406 & $0.066851^{\mathrm{a}}$ & 0.022816 \\
D(SMOVE(-2)) & -0.018079 & -0.012140 & -0.026407 & -0.019916 & $-0.057498^{\mathrm{b}}$ & 0.016319 \\
D(SP_VIX(-1)) & $0.069523^{\mathrm{a}}$ & $0.069197^{\mathrm{a}}$ & $0.064709^{\mathrm{a}}$ & $0.060417^{\mathrm{a}}$ & $0.036469^{\mathrm{b}}$ & $-0.126298^{\mathrm{a}}$ \\
D(SP_VIX(-2)) & 0.008106 & 0.004212 & -0.029564 & -0.008439 & -0.012329 & $-0.097011^{\mathrm{a}}$ \\
\hline
\end{tabular}

Notes: System II does not include the non-risk variable oil price Variables are all first differences of logarithms. Superscripts a, b and c represent significance at the $1 \%, 5 \%$ and $10 \%$ levels, respectively. 
Table 8: Block Exogeneity Wald Tests for System II (full period)

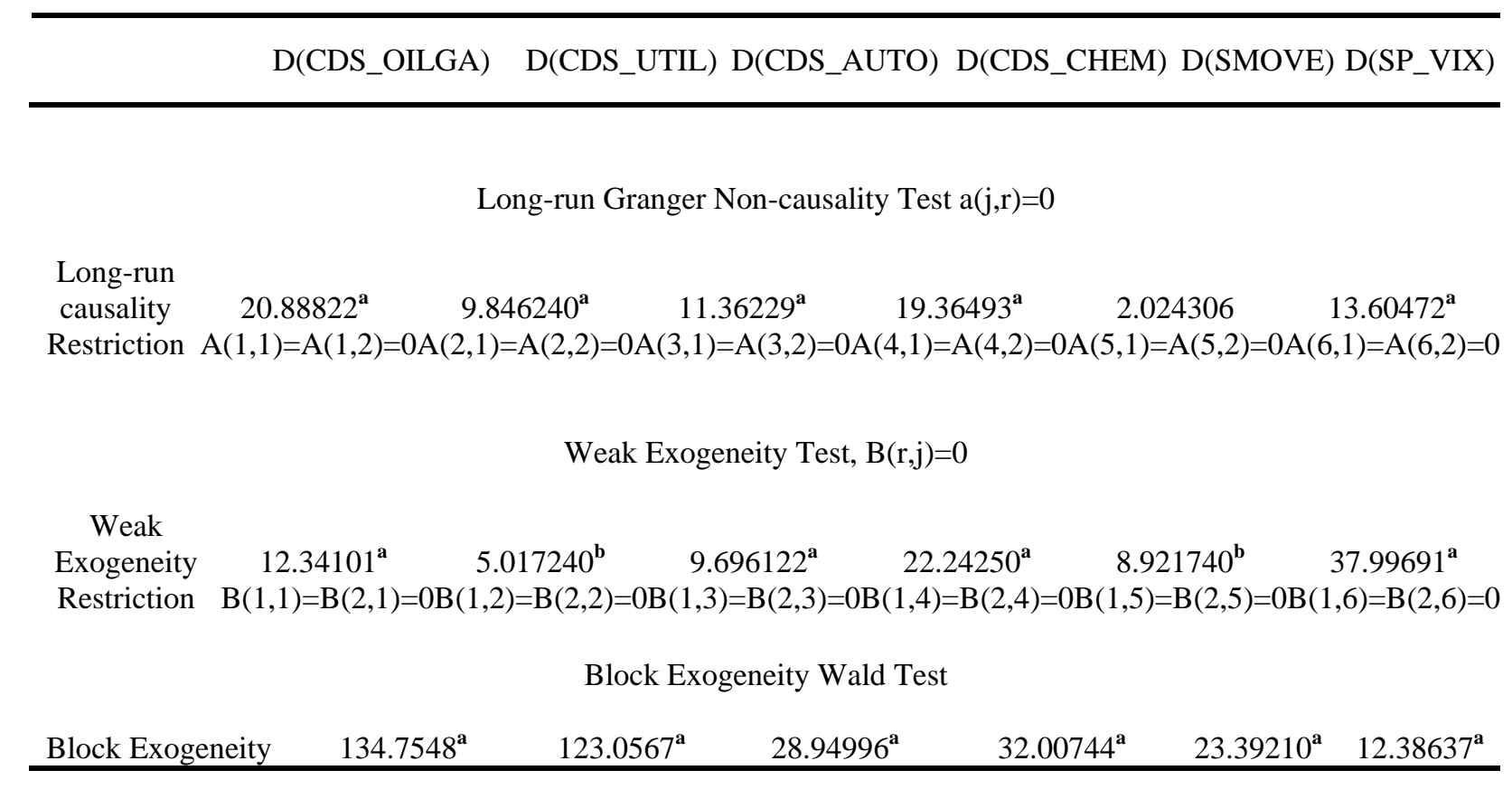


Table 9: Variance Decomposition

\begin{tabular}{|c|c|c|c|c|c|c|}
\hline Period & CDS_OILGA & CDS_UTIL & CDS_AUTO & CDS_CHEM & SMOVE & SP_VIX \\
\hline \multicolumn{7}{|c|}{ DV of CDS_OILGA } \\
\hline 1 & 100.0000 & 0.000000 & 0.000000 & 0.000000 & 0.000000 & 0.000000 \\
\hline 50 & 69.59238 & 6.625924 & 0.981198 & 1.058233 & 1.248252 & 20.49401 \\
\hline \multicolumn{7}{|c|}{ DV of CDS_UTIL } \\
\hline 1 & 37.15866 & 62.84134 & 0.000000 & 0.000000 & 0.000000 & 0.000000 \\
\hline 50 & 38.98698 & 45.03182 & 0.870076 & 0.761704 & 1.205479 & 13.14395 \\
\hline \multicolumn{7}{|c|}{ DV of CDS_AUTO } \\
\hline 1 & 8.703190 & 2.881302 & 88.41551 & 0.000000 & 0.000000 & 0.000000 \\
\hline 50 & 9.178839 & 11.36553 & 65.40236 & 3.947938 & 1.949611 & 8.155727 \\
\hline \multicolumn{7}{|c|}{ DV of CDS_CHEM } \\
\hline 1 & 4.631845 & 2.281287 & 0.039881 & 93.04699 & 0.000000 & 0.000000 \\
\hline 50 & 20.17204 & 7.057288 & 4.917429 & 50.99282 & 7.636346 & 9.224075 \\
\hline \multicolumn{7}{|c|}{ DV of SMOVE } \\
\hline 1 & 1.352944 & 0.885158 & 0.048982 & 0.055044 & 97.65787 & 0.000000 \\
\hline 50 & 2.217500 & 3.767189 & 0.050246 & 1.577486 & 89.11342 & 3.274161 \\
\hline \multicolumn{7}{|c|}{ DV of SP_VIX } \\
\hline 1 & 9.649101 & 2.717321 & 1.096133 & 0.038557 & 3.951231 & 82.54766 \\
\hline 50 & 22.08538 & 4.307342 & 2.386359 & 1.043024 & 6.279235 & 63.89866 \\
\hline
\end{tabular}




\section{Table 10: Cointegration Equation for System II (subperiod)}

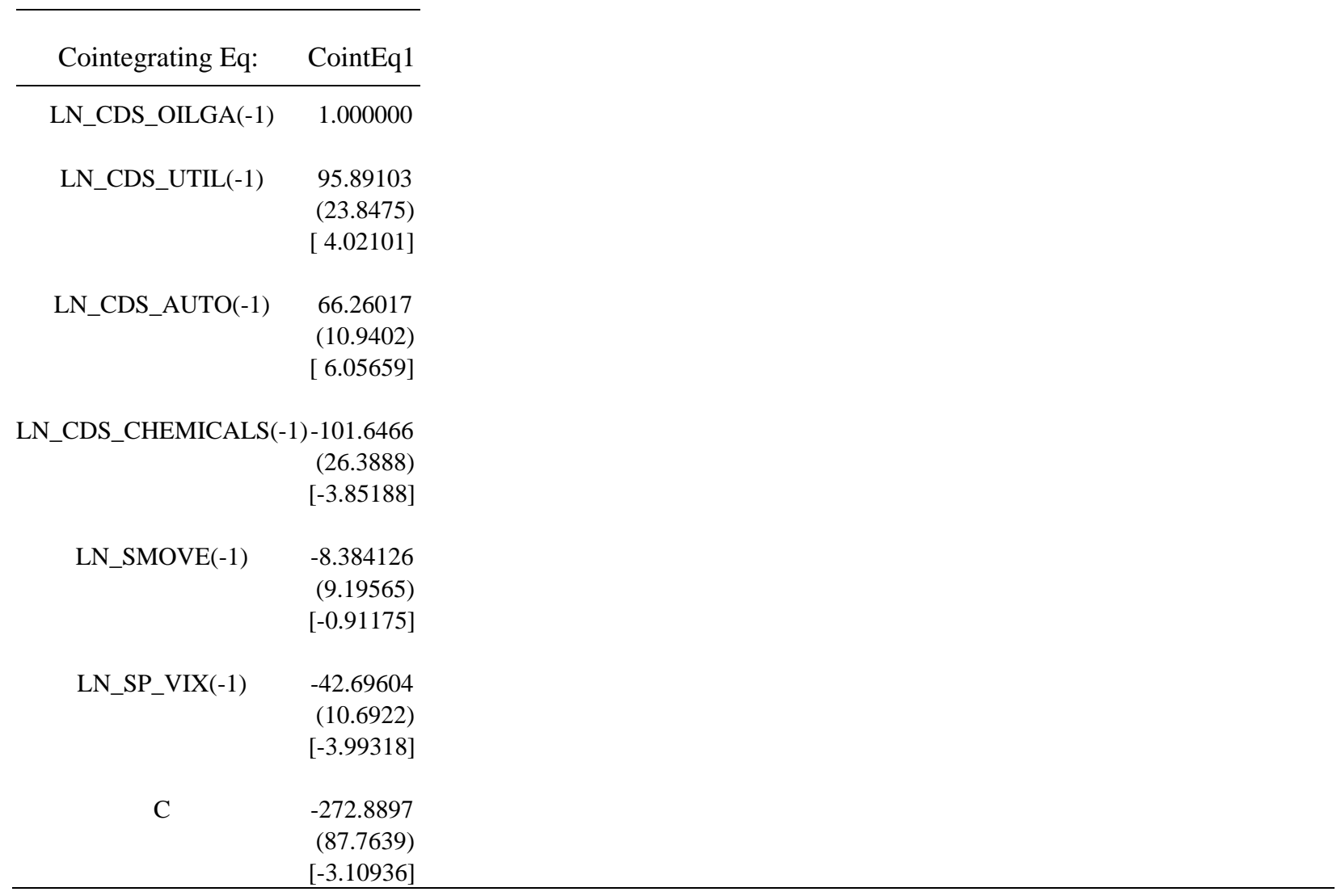

Notes: Cointegration equation for System II with the subperiod 7/01/2009-1/21/2011. 
Table 11: VEC for System II (subperiod) [Tengdong: later we will delete this table]

\begin{tabular}{|c|c|c|c|c|c|c|}
\hline Error Correction: & D(CDS_OILGA) & D(CDS_UTIL) & D(CDS_AUTO) & D(CDS_CHEM) & D(SMOVE) & D(SP_VIX) \\
\hline CointEq1 & -0.000157 & $-0.000277 \mathbf{a}$ & $-0.001356 \mathbf{a}$ & $-0.000226 \mathbf{b}$ & $3.72 \mathrm{E}-05$ & 0.000148 \\
\hline $\mathrm{D}(\mathrm{CDS}$ _OILGA(-1)) & 0.022965 & -0.003357 & -0.102230 & -0.023581 & 0.023101 & -0.135991 \\
\hline D(CDS_OILGA(-2)) & $-0.389523 \mathbf{a}$ & 0.002970 & -0.030611 & 0.021335 & 0.031684 & $-0.215675 c$ \\
\hline D(CDS_UTIL(-1)) & 0.168905 & $0.187703 \mathbf{b}$ & 0.014193 & 0.126656 & -0.115713 & -0.151212 \\
\hline D(CDS_UTIL(-2)) & $0.293143 b$ & 0.042988 & 0.016974 & 0.001842 & -0.139735 & 0.214114 \\
\hline D(CDS_AUTO(-1)) & 0.009579 & -0.001791 & $0.376339 \mathbf{a}$ & 0.024584 & -0.004167 & 0.040698 \\
\hline D(CDS_AUTO(-2)) & -0.015770 & -0.021293 & -0.070307 & -0.034452 & 0.035032 & -0.065470 \\
\hline D(CDS_CHEM(-1)) & 0.084588 & 0.044580 & -0.111087 & 0.118446 & -0.005895 & $0.607216 \mathbf{a}$ \\
\hline D(CDS_CHEM(-2)) & 0.101412 & -0.020512 & 0.256011 & 0.058963 & 0.119929 & -0.234813 \\
\hline D(LN_SMOVE(-1)) & 0.015246 & 0.019918 & 0.048812 & 0.021111 & 0.032175 & 0.123037 \\
\hline D(SMOVE(-2)) & -0.031927 & -0.015406 & $-0.125942 \mathbf{b}$ & -0.036210 & -0.076164 & -0.056164 \\
\hline D(SP_VIX(-1)) & 0.029643 & $0.029019 c$ & -0.017386 & $0.035354 \mathrm{c}$ & 0.054472 & $-0.113345 c$ \\
\hline D(SP_VIX(-2)) & $\begin{array}{r}0.019207 \\
(0.02906) \\
{[0.66085]}\end{array}$ & $\begin{array}{c}0.006048 \\
(0.01670) \\
{[0.36204]}\end{array}$ & $\begin{array}{r}-0.028073 \\
(0.04180) \\
{[-0.67153]}\end{array}$ & $\begin{array}{r}-0.000942 \\
(0.01909) \\
{[-0.04931]}\end{array}$ & $\begin{array}{c}0.043359 \\
(0.03523) \\
{[1.23081]}\end{array}$ & $\begin{array}{r}-0.020262 \\
(0.05846) \\
{[-0.34658]}\end{array}$ \\
\hline R-squared & 0.156413 & 0.139503 & 0.243121 & 0.134006 & 0.020834 & 0.048081 \\
\hline Adj. R-squared & 0.130785 & 0.113361 & 0.220127 & 0.107697 & -0.008913 & 0.019161 \\
\hline Sum sq. resids & 0.399182 & 0.131860 & 0.825873 & 0.172300 & 0.586463 & 1.615216 \\
\hline S.E. equation & 0.031790 & 0.018271 & 0.045725 & 0.020885 & 0.038532 & 0.063946 \\
\hline F-statistic & 6.103226 & 5.336420 & 10.57334 & 5.093601 & 0.700377 & 1.662590 \\
\hline Log likelihood & 834.7125 & 1060.678 & 686.3997 & 1006.110 & 756.2352 & 549.5600 \\
\hline Akaike AIC & -4.028003 & -5.135676 & -3.300979 & -4.868186 & -3.643310 & -2.630196 \\
\hline Schwarz SC & -3.900193 & -5.007866 & -3.173169 & -4.740376 & -3.515500 & -2.502386 \\
\hline Mean dependent & -0.000964 & -0.000280 & -0.005709 & -0.001599 & -0.001715 & -0.000871 \\
\hline S.D. dependent & 0.034098 & 0.019404 & 0.051778 & 0.022110 & 0.038361 & 0.064568 \\
\hline
\end{tabular}


Determinant resid covariance

Log likelihood

Akaike information criterion

Schwarz criterion

Notes: Superscript ${ }^{\text {a }}$ represents significance at $1 \%$, b at $5 \%$, and c at $10 \%$.
2.53E-19

5261.795

$-25.37645$

$-24.54077$ 